\title{
A Comparative and Explore on the Training Mode of Aviation Talents Between China and America
}

\author{
Ying Xu \\ School of Aircraft Engineering, Nanchang Hangkong University, Nanchang, China
}

\section{Email address:}

tn416ky@126.com

\section{To cite this article:}

Ying Xu. A Comparative and Explore on the Training Mode of Aviation Talents Between China and America. Science Innovation. Vol. 7, No. 2, 2019, pp. 70-75. doi: 10.11648/j.si.20190702.14

Received: April 22, 2019; Accepted: May 26, 2019; Published: June 15, 2019

\begin{abstract}
The improvement of education quality is an teaching reform activity which involves the innovation and change of many aspects in professional construction. To work out the problem of teaching quality in higher education, ensure and improve the quality of personnel training, we must realize the change in the professional construction and the teaching ideas, and hope that teachers, students and managers can try their best to cooperate well to promote the management. This research compared and analyzed the training target, training mode, Teaching method and medium on aviation education among the famous aircraft universities between China and America countries through field investigation, case method and comparative method. Combined with the national project of "Pilot project for comprehensive reform of aircraft power engineering", show the exploration of improving the quality of personnel training in many ways, Provide some reference for aviation talent training.
\end{abstract}

Keywords: Personnel Training, Quality, Aviation, Innovation Ability, Measures

\section{中美航空类专业人才培养模式比较分析与探索}

许瑛

南昌航空大学飞行器工程学院, 南昌, 中国

邮箱

tn416ky@126.com

摘要: 教育质量的提升是一项涉及专业建设多方面创新的教学改革活动, 破解高等教育教学质量困境, 保障和提升人 才培养质量, 必须在专业建设和教学理念上实现改革, 需要教师、学生、管理者各尽其责合力推进。采用实地调研法、 案例研究法和比较研究法, 对美国著名航空大学航空类人才培养目标、培养模式、教学方法进行了分析和研究, 结合 本学院“飞行器动力工程专业综合改革试点” 国家级项目, 实施了多途径提高人才培养质量的探索, 为航空类人才培养 提供一些参考。

关键词: 人才培养, 质量, 航空, 创新能力, 举措

\section{1. 引言}

自改革开放以来，我国高等教育实现了跨越式发展， 高等院校的数量和人数位居世界前列。习近平总书记在北 京大学师生座谈会上的讲话中指出“高等教育是一个国家
发展水平和发展潜力的重要标志。今天, 党和国家事业发 展对高等教育的需要, 对科学知识和优秀人才的需要, 比 以往任何时候都更为迫切。”“规模扩张并不意味着质量和 效益增长, 走内涵式发展道路是我国高等教育发展的必由 之路”[1]。 
提高人才培养质量, 不仅是我国高校当前面临的挑战, 也是全球范围内高等教育共同的课题。“学生在大学里学 什么、能学到什么、学得怎么样, 同大学人才培养体系密 切相关”。“人才培养体系必须立足于培养什么人、怎样培 养人这个根本问题来建设, 可以借鉴国外有益做法, 但必 须扎根中国大地办大学 [1]。

在江西省百千万人才交流计划项目资助下，笔者于 2013年赴美国Embry-Riddle Aeronautical University（安博 瑞德航空航天大学) 访学一年, 亲身感受了该校航空类人 才培养过程, 考察了安博瑞德航空航天大学教育、科研、 学生科技活动及学生管理等环节, 结合我校飞行器动力工 程、飞行器设计等专业人才培养的实际举措, 对比了中美 两所航空类高校在人才培养理念、培养目标、师资队伍、 教学方法、科技创新、学生管理的异同, 结合我校飞行器 动力工程专业的国家级“专业综合改革试点”项目, 实施了 多途径加强内涵建设的探索, 为高等院校人才培养质量的 提高提供一些参考。

\section{2. 两所学校概况}

Embry-Riddle Aeronautical University(简称ERAU)是 一所私立大学, 建于 1925 年的, 是美国唯一一所航空航天 专业大学。该校有三个常规校区, 佛罗里达州代托纳比奇 主校区(如图1所示)、亚利桑那州分校区和面向国际化培养 的世界校区。笔者访学的佛罗里达主校区学生人数有 8000 多人, 主干特色学科是Aviation (飞行技术) 和Aircraft engineering (航空工程)、Aerospace (航天工程), 其中 飞行技术专业全美国排名第一, 航空工程、航天工程全美 国排名前三位。学校设有College of Aviation 航空学院(如 图2所示), College of Engineering 工学院、College of Arts and Sciences 文理学院, College of Education 教育学院。

A飞行技术专业为航空学院的主干专业, 该校三分之二的 学生就读于该专业, 航空工程和航天工程专业归属于工学 院[2]。

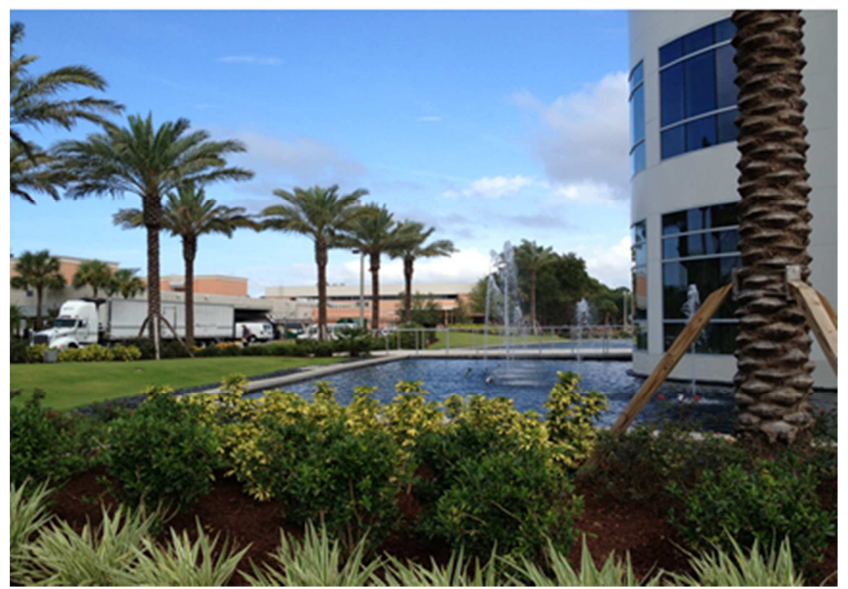

图1 ERAU代托纳比奇校区。

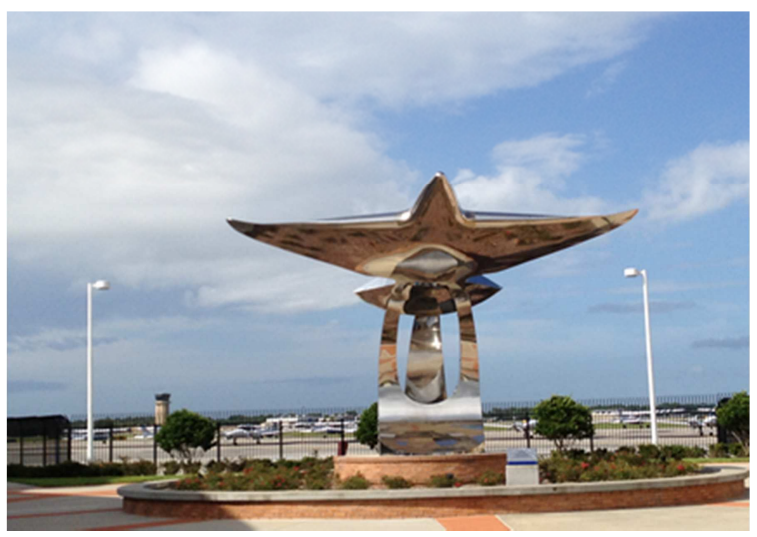

图2 ERAU的航空学院外景。

南昌航空大学是一所以工为主, 工、理、文、管、经、 法、教、艺等学科协调发展的多科性大学, 有 60 多年建校 历史。飞行器工程学院是我校的专干航空类专业学院, 其 主干专业为飞行器动力工程、飞行器设计工程等[3]。

\section{3. 两校人才培养计划的比较}

南昌航空大学 (以下简称昌航) 航空类专业的培养目 标是：培养思想素质好、基础扎实、实践能力强、适应经 济社会发展需要、具有创新精神, 掌握具备飞行器动力装 置或飞行器动力装置控制系统等方面的知识, 能在航空、 航天、交通、能源、环境等部门从事飞行器动力装置及其 它热动力机械的设计、研究、生产、实验、运行维护和技 术管理等方面工作的应用型高级专门人才。本专业学生主 要学习有关飞行器动力装置的基础理论和基本知识, 受到 机械工程设计、实验测试和计算机应用等方面的基本训练, 具有飞行器动力装置及控制系统的设计、实验和运行维护 等方面的基本能力[3]。

ERAU航空工程专业的培养目标是：为学生提供解决 飞机或超级飞行器设计、推进和系统中最复杂问题挑战的 技能, 为学生掌握全面专业知识的教育, 为将来从事有成 效的职业和履行公民的义务做必要的准备, 特别是为航空、 航天工程及其相关领域的需要培养人才, 其重点对象是为 大气和太空飞行器的任务导向 $[2,4]$ 。

昌航培养计划对学生的素质、知识和能力主要从思想 品德、基础知识、专业知识、综合能力、文献资料检索、 科学研究、实际工作能力、人文修养、组织管理能力、语 言表达能力、计算机应用能力、健康体魄等 12 个方面提出 了要求[3]。

ERAU培养计划对学生的工程职责和方法、专业行为 和创新、技术交流、综合教育、基础知识和数学方法、工 程力学、空气动力学、工程热力学、结构和材料、电工学、 航天学、实验和数据处理、设计能力等 14 个方面提出了要 求[4]。

昌航航空专业的主要课程涉及航空宇航科学技术、机 械工程、力学、动力工程与工程热物理等领域。核心课程 为力学、机械原理、机械设计、空气动力学、飞行器结构 力学、航空发动机原理、飞行器结构设计、飞行器控制系 统设计等[3]。 
ERAU航空专业的主要课程领域与昌航基本相同, 他 们在航空类课程的基础上, 增加了航天类课程, 在课程设 置上比我们多了技术情报写作、专业演讲等课程, 而且, 这些课程都是在一年级新生中开设。昌航的课程设置在公 共必修课方面的份量很重, 基础扎实。两所学校的航空类 专业学制相同, 都为四年, ERAU飞行器器动力工程专业 的总学分为 126 , 我校的总学分为 195 , 国内的学分要求比 较高 $[2,4]$ 。

\section{ERAU的教学方法}

笔者在ERAU跟随航空工程、航天工程、飞行技术专 业系统地学习了Applied Aviation Research Methods 飞行 器设计方法与应用、Human Factors in the Aviation/Aerospace Industry航空航天中的人因工程、 Principle and Structure of Aero-engine航空发动机原理与结 构、Robotics Technologies for Unmanned Vehicle Systems 无人车辆中的机器人技术、 Intelligent Control Systems 智 能控制系统等多门课程, 明确了这些专业的教学过程和方 法。

(1) 课堂教学: ERAU的许多专业课都是小班上课为 主(如图3所示), 每门课程选课的学生数在 20 人左右。上课 教室都是根据不同专业的需要设置的, 其有特色不尽相同, 有许多专业课的教室内摆放了相关专业实验设备, 增加学 习过程中的感性认识, 也便于实验教学。也有上大课的教 室, 如高等数学等公共课程, 大课人数最多的为 60 人左右 [2]。

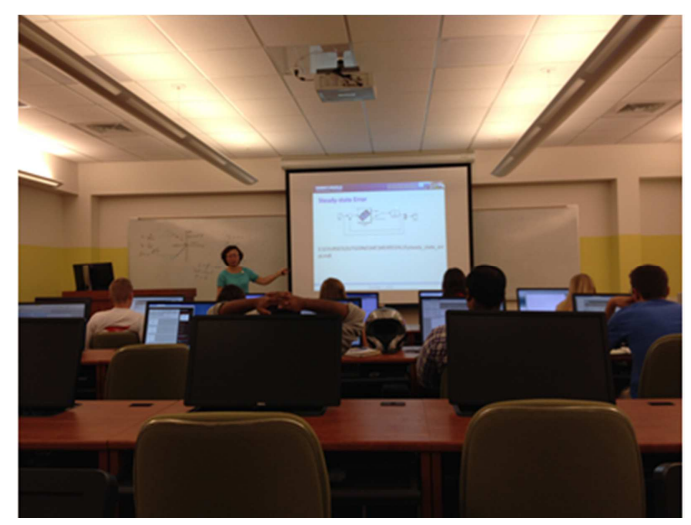

图3 ERAU的课堂教学。

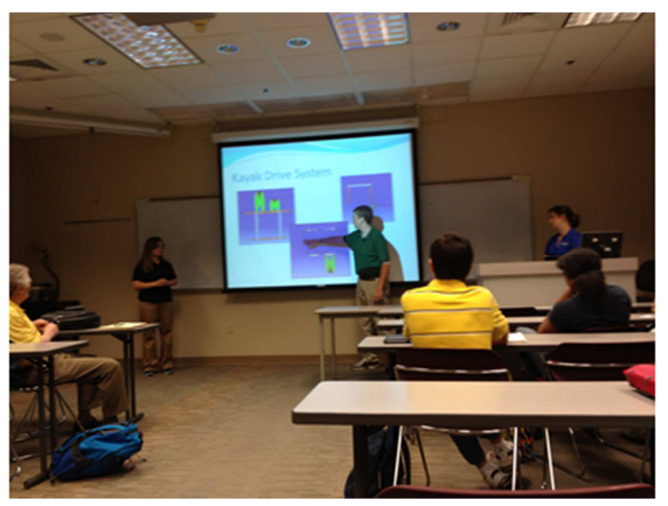

图4 ERAU学生在课堂上交流自己的创新作品。
（2）教学条件: 每个教室的教学配备齐全, 教学条 件先进, 特别是投影设备的高清化, 可直接将教师的教案 手稿、书直接投影在屏幕上, 不需要任何加工。大部分课 程所用的教材并非局限在一本教科书上, 教师给学生推荐 多本教材, 围绕所讲内容, 多本教材并用, 学生可根据需 要选择自己所需的参考书, 不要求学生一定要有指定教材。

(3) 教学手段: 信息化教学是该校广泛采用的教学 方式, 每门课的教学资源全部对选课的学生开放, 包括教 学计划、PPT、教案、讲义、辅导资料、布置作业、考试 计分标准等。选课的学生可以随时网上学习, 师生互动很 强。

（4）教师的教学方法: 教师的教学方法很灵活, 老 师和学生都是教学的主体, 教师可以按照教学计划讲, 也 可以随时改变计划。课堂上学生可以随时提问, 老师欣然 耐心解答, 师生互动气氛变得轻松有趣, 上课不感觉乏味 无趣。教师并不依赖PPT, 几乎没有老师整堂课都用PPT 的, 教师板书的内容有很多。课堂教学只是画龙点睛的过 程, 满堂灌的现象不多。学生需要在下面花时间复习, 在 这一点上, 美国学生与中国学生的区别很明显, 他们会主 动自觉的课后复习, 做作业。特别是每门课结束时都会有 各组学生的小论文交流(如图4所示), 课题是老师指定大范 围, 具体题目由学生自己定, 各组学生都会认真地准备, 全组站在讲台上轮换讲述, 然后接受老师和其他同学提问。 另外, 教师的教学效果好坏的评判完全取决于学生评教, 评教结果在教师业绩及晋升中占很大的比例, 即使学生评 教不够客观, 也不会改变教师业绩考评结果。

（5）学分制选修：完全意义上的学分制，学生可以 跨专业选课, 不受学科和专业限制, 只要学分满足要求就 可以, 每学期选课的学分数有限制, 比如, 每学期规定学 分底限和高限, 学习成绩优秀的学生（专业排名前 $15 \%$ ) 每学期可以有一定学分的学费减免。

（6）学期设置: 每年设置3个学期, 即春季学期、夏 季学期和冬季学期。新学年从每年的 8 月中下旬开始到 12 月中旬为一个学期, 1 月 10 日前后到 5 月 10 日前后为春季学 期, 另一个学期在每年的 5 月至 8 月暑假期间, 专门对暑假 选课的学生开设, 暑假选课的学生不多。暑假大约三个月 的长度, 为学生提供足够时间的实习机会。学生自己找实 习单位, 实习课程的学分计入课程总学分, 相应学费可以 减免, 既为学生提供了社会实践的机会, 又减轻了学生负 担。

\section{ERAU的航空文化活动}

\section{1. 学生中的现役军人}

Embry-Riddle Aeronautical University（ERAU）与美 国五大军种的空军、海军、陆军、海军陆战队, 海岸警卫 队联系密切, 五大军种多年来将ERAU作为军人培养的首 选高校, 这些军人学生大多是在航空学院学习, 经常在校 园中会看到他们集训的身影(如图5所示)。每当看到那些身 着军装的学生整齐认真训练的样子, 许多学生都会投去敬 慕的目光, 长期的潜移默化, 也增强了学生的爱国情怀。 学校经常为军人学生举办一些活动(如图6所示), 有相当一 
部分学生是退伍军人或预备役军人, 这些学生在奖学金、 评优、就业方面受到了优待。

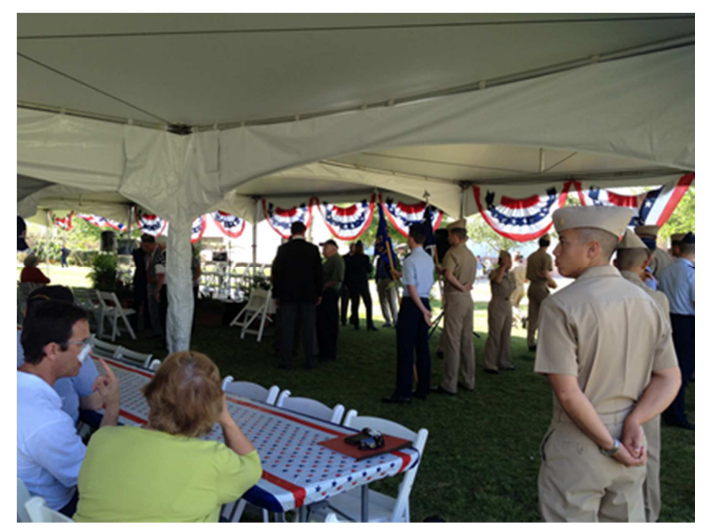

图5 ERAU的校园军事活动掠影。

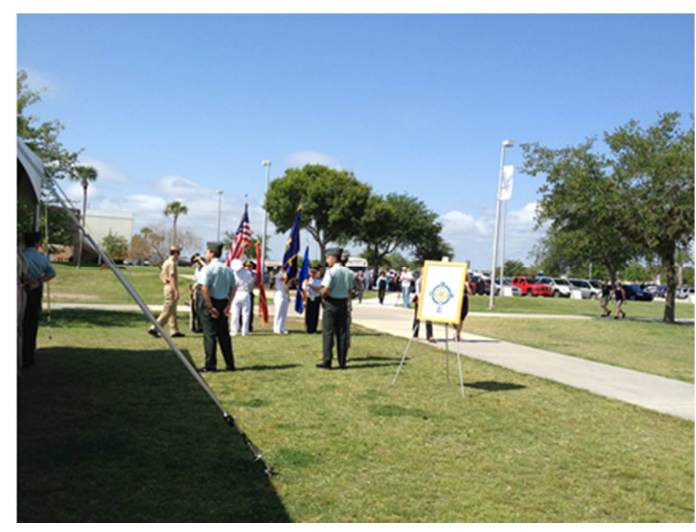

图6 ERAU的现役军人集训活动。

\section{2. 丰富多彩的航展}

佛罗里达州是海滨之州, 也是航空文化特色厚重之州, 大大小小的航展时常蒙绕着ERAU。从奥兰多的公务机展 (如图7所示), 到代托纳比奇的军机列队表演, 到德兰的通 用飞机竞技赛, 再到威斯康星奥什卡什的EAA飞来者大会 (如图8所示), 知名飞机制造公司波音、空客、庞巴迪等各 类名目繁多、特点各异的飞机让人大开眼界。航展上有激 动人心的飞行表演, 有世界上数量最多、机型最全的飞机 展示, 有专业学术论坛、科普与航空体验活动, 有露天音 乐会, 配上充满战斗气氛焰火表演, 着实营造了一个是航 空的殿堂与乐园。

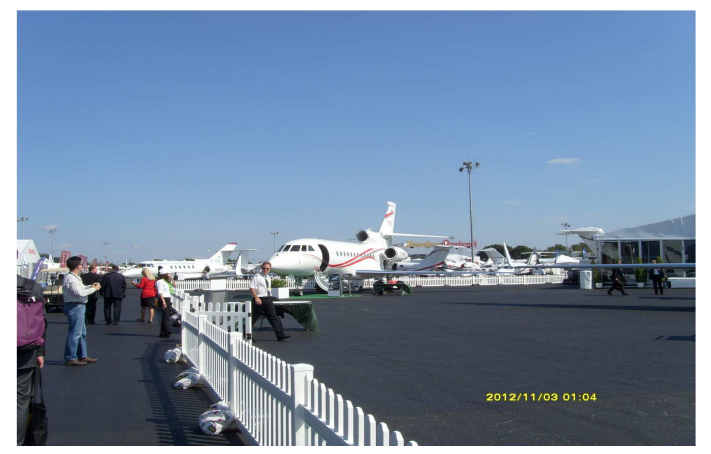

图7 美国佛罗里达州奥兰多公务机展。

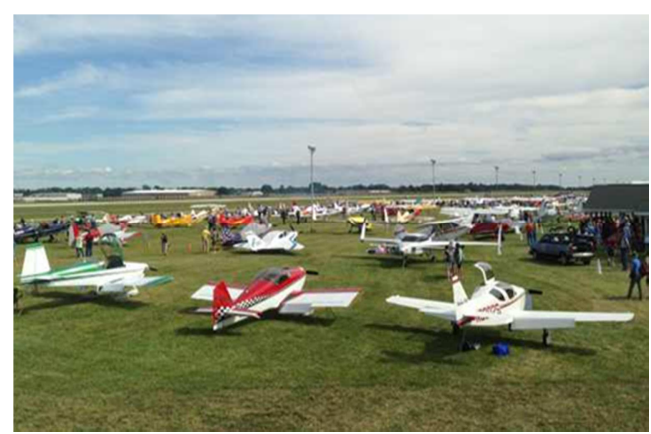

图8 2016年美国EAA飞来大会掠影。

\section{3. 学生的课外科技活动}

ERAU的学生科技制作很突出, 许多学生都有参赛的 机会, 而且获奖比较多, 有各种级别的飞行器设计大赛、 飞行竞技比赛、机器人比赛、工程车辆大赛等活动, 许多 学生参加教师的科研项目, 实践活动和动手制作机会很多, 同时, 许多通用飞机制造企业也为学生提供了体验私人飞 机制造的全过程的机会。无论是学士还是硕士, 学习期间 重要的环节是实习, 实习可以自己定时间和长度安排, 学 校不做统一规定。

学校对一年级新生的管理相对严格, 要求新生统一住 校一年, 而对高年纪学生的管理相对宽松, 衣食住行不做 统一规定, 这样, 学生进入高年级后学习、生活实行自我 管理。

\section{6. 昌航人才培养的具体措施}

根据昌航专业设置的特点, 学院组织教师曾到成飞、 西飞、洪都、襄阳航宇等航空企业院所调研, 通过调研明 确了企业及科研院所对高校毕业生的能力需求。同时, 通 过和其他高校进行学习交流，结合本校获得的国家级“专 业综合改革试点”项目, 按照准确定位、注重内涵、突出 优势、强化特色的原则, 通过优化人才培养模式、更新教 学方法、提升教师素质、培养学生创新能力、加强教学管 理等重要环节的综合尝试, 试图推动人才培养质量的全面 提升。

\section{1. 教育理念的更新及专业定位}

遵从“教育要面向现代化、面向世界、面向未来”的时 代精神, 吸收国际上先进的教育理念, 借鉴国外院校人才 培养中灵活的教学模式, 结合飞行器类专业的特点及学校 的自身条件, 提出以培养学生三维创新设计能力为主线的 教学改革模式, 以此设置专业课程体系, 并结合课题组成 员的教学、科研工作开展教学研究。在“厚基础、宽口径、 强能力、重实践、有特色”的原则指导下, 构建创新型、 个性化的人才培养体系, 突出人才培养中的行业取向 [5-7]。

\section{2. 以学生为主体的研讨教学方式创新}

采取课堂讲授与讨论相结合的方式进行教学。分别在 “计算机辅助飞机设计”、“航模设计与制作”、“航空制造技 术”等课程中, 以教师讲解为主, 辅以学生自学、阅读文 
献资料, 进行课堂讨论。教师要事先分配研讨任务, 明确 具体分工, 确定讨论焦点, 告知资料检索途径; 小组利用 业余时间进行准备及研究工作, 在研讨课上开展小组之间 的讨论交流, 由教师组织各组发言并予以现场评议。在师 生中进行思想的交流和碰撞, 进一步提高学生对所学专业 知识的认识, 提高本科生的理解能力、辨别能力和交流能 力 $[6]$ 。

\section{3. “项目化”的科研创新训练}

将学生创新实践创新能力训练分为三个阶段进行, 即 基础理论学习阶段、实践训练阶段、参加科技竞赛阶段。 理论学习阶段主要学习创造学基础知识, 如创造性思维方 式、创造技法及其训练、创新课题表达等内容。结合大学 生科技竞赛活动, 如全国数字化创新设计大赛、全国大学 生机械创新设计大赛、瑞萨超级MCU模型车大赛, 对学 生进行分类教学。按照学生的航模队、机器人协会、3D 设计小组等社团组织, 分别给学生安排相应的课程学习及 培训计划, 将学生创新能力培养目标确定为三个方面, 即 机械结构创新能力、三维数字化能力、系统运动分析及运 动控制能力等, 通过参赛培养学生创新思维和解决工程实 际问题的能力，加强团队交流及协作精神 [7]。

\section{4. “教研一体化”师资平台的构建}

借助飞行器主专业和主学科的优势, 结合培养计划设 置的 “科研创新训练”课程, 一方面吸收优秀本科生参加 老师的科研课题, 如参加课题组成员的“无人靶机”、“弹 射座椅姿态控制技术”等项目, 参与三维总体及结构设计、 系统实验等任务; 另一方面, 构建教学、科研、管理相结 合的师资队伍, 我们的师资平台, 既有教学科研一线的教 师, 也有学生管理线上的教师。项目组成员洪书生、蒋阳 除了每学期指导学生参赛外, 还利用暑假开设航模设计与 制作集训班, 实现教、学、做一体化 $[3,8]$ 。

\section{5. 跨学院、跨专业的团队协作}

在学生创新能力培养中, 根据不同赛事组建跨学院、 跨专业的项目组, 加强不同学院, 学科、专业之间的渗透 及协作。在3D大赛中飞行器专业的学生承担结构建模、装 配及仿真, 艺术学院工业设计的学生承担渲染、造型设计 的任务; 在机械创新大赛中, 飞行器专业的学生承担机械 结构设计与制作, 信工学院的学生承担控制硬件的设计与 调试等工作; 无人机项目中飞行器专业学生完成气动外形 设计, 体育学院学生参加试飞等工作, 通过多样化的合作 性学习协作, 增进了不同学院、不同专业之间的合作与交 流，大大提高了科技竞赛项目的参赛效果 $[8,9]$ 。

\section{6. 教学管理水平的提高}

创新能力培养不仅是教学改革的尝试, 也是对教学管 理水平的考验, 对学院的教学管理水平提出了更高的要求。 据此, 我们强调以竞赛为类别的学生管理, 按项目组织参 赛小组, 注重贯穿激励机制, 尊重学生的兴趣爱好和个性 特点, 为项目开展打下良好的基础。在学生科研创新训练 环节的考核上采用灵活的考核方式和有侧重点的倾斜机
制, 调动学生科研创新的积极性, 使项目研究得以顺利开 展 $[10,11]$ 。

\section{7. 结论}

通过Embry-Riddle Aeronautical University和南昌航空 大学飞行器工程学院航空类专业的培养过程比较分析, 明 确了两所航空院校办学的特点。ERAU显著的原汁原味的 航空航天特色, 特别是飞行技术、航空工程及航天工程专 业的世界领先优势和规范化的教育理念、多元的社会文化、 独特的教育体系和人性化的教学模式, 为南昌航空大学航 空类专业的发展提供了很好的示范作用; ERAU厚重的航 空文化氛围和创新型人才培养模式, 解决了部队、航空、 国防人才的需求, 其先进教学理念和教学模式拓宽了我们 的视野。但是, 外国学生的数学基础普遍薄弱, 理论计算 和分析能力有待提高。

南昌航空大学航空类专业办学历史悠久, 积累了很多 成功的经验, 形成了自己的办学特点。我校航空类专业学 生, 基础知识牢固, 专业知识扎实, 近五年来, 学院组织 学生参加国际航空模型锦标赛、国际飞行器设计大赛, 全 国机械设计创新大赛、全国挑战杯大赛等各类比赛, 全院 学生获得挑战杯全国大学生课外学术科技作品竞赛“二等 奖”等省部级以上奖励 495 人次, 授权专利 53 项。学生连续 5 年参加全国三维数字化创新设计大赛, 获得全国3D创新 设计大赛总决赛一等奖5项。学生参加科技制作活动的兴 趣和热情不断高涨。但是我们学生的科技论文写作语言能 力还有待提高, 课堂教学中师生自由互动比较少, 实践环 节的条件不够先进, 航空文化氛围的营造还有许多工作要 做。今后在保持和发展专业优势、提高师资队伍素质、开 展科学研究、扩大国内外合作交流的同时, 主动把这些基 础转化为提高人才培养质量的新优势。

\section{致谢}

本文为江西省社会科学基金重点项目《以专业综合改 革为契机的人才培养质量提升机制研究》(CC201306276) 的阶段性成果之一。

\section{参考文献}

[1] 习近平在北京大学师生座谈会上的讲话 [N], 人民日 报, 2018,05,03。

[2] http://erau.edu/about/l-about (accessed 2018-10-4) [Z].

[3] 南昌航空大学培养计划[Z], 2015版。

[4] Embry-Riddle Aeronautical University catalog[Z], 2016-2017.

[5] 钱学森. 我们办学要有加州理工学院的科技创新精神 $[N]$, 人 民日报,2009,11,13。

[6] 张德江. 人才培养质量的影响因素与对策探析[J].中国大学 教学, 2012 (2)：11-13。 
[7] 顾秉林,王大中,汪劲松.创新性实践教育--基于高水平学科 建设的创新人才培养之路 [J]. 清华大学教育研究, 2010,01:1-5。

[8] http://www.harvard.edu (accessed 2018-12-2) [Z].
[9] http://www.stanford.edu (accessed 2018-11-30) [Z].

[10] 杜玉波.把握新常态下的高教发展[N].光明日报,2015,03,02。

[11] 陈治亚.推进高校人才培养质量提升的路径分析[J].中国高 等教育, 2014（11）：12-17。 